\title{
A review of the pathology and treatment of canine respiratory infections
}

This article was published in the following Dove Press journal:

Veterinary Medicine: Research and Reports

26 June 2012

Number of times this article has been viewed

\section{Miranda D Vieson* \\ Pablo Piñeyro* \\ Tanya LeRoith}

Department of Biomedical Sciences and Pathobiology, Virginia-Maryland Regional College of Veterinary Medicine, Virginia Tech University, Blacksburg, VA, USA

*These authors contributed equally to this work
Correspondence: Tanya LeRoith Virginia-Maryland Regional College of Veterinary Medicine, Virginia Tech University, Department of Biomedical Sciences and Pathobiology, 225 Duckpond Drive, Blacksburg, VA 2406I, USA

Tel +I 5402317627

Fax + I 540 23I 6033

Email tleroith@vt.edu
Abstract: Numerous infectious agents are responsible for causing primary or secondary respiratory disease in dogs. These agents can cause upper or lower respiratory infections commonly observed in veterinary practices. Clinical signs might vary from mild dyspnea, sneezing, and coughing to severe pneumonia with systemic manifestations. Depending on the etiologic agent, the gross and microscopic changes observed during these infections can be rather unspecific or have highly characteristic patterns. While histopathology and cytology are not always required for diagnosis of respiratory infections, they are often useful for establishing a definitive diagnosis and identifying specific etiologic agents. Research regarding epidemiology, pathogenesis, diagnostics, and clinical manifestations related to these infectious pathogens provides valuable information that has improved treatments and management of the diseases they cause. This review discusses the epidemiology, general clinical characteristics, and pathologic lesions for some of the important viral, bacterial, fungal, and parasitic etiologies of canine respiratory disease.

Keywords: bacterial, fungal, parasitic, pneumonia, rhinitis, tracheobronchitis, viral

\section{Introduction}

The respiratory tract is constantly exposed to infectious agents that can reach the upper and lower respiratory tract aerogenously or hematogenously. The invasion of the respiratory tract by deleterious pathogens is normally prevented by physical, chemical, and immunologic mechanisms including mucus and mucociliary clearance, various innate antimicrobial factors, alveolar macrophages, and the pulmonary immune response. Some respiratory pathogens cause infection as secondary, opportunistic invaders after host defense mechanisms have been disrupted by other factors (eg, immunosuppression, environment, stress, toxins, and concurrent infection). There are also primary pathogens that have developed mechanisms or virulence factors enabling them to disrupt and evade the host defenses without predisposing factors. Regardless of whether agents affect the upper or lower respiratory tract, the host response will vary based on the severity of infection, pathogenic mechanism of the pathogen, and immune status of the host. Thus, morphological changes will similarly vary from mild circulatory changes such as mucosal or pulmonary edema and congestion, to severe mucosal or pulmonary inflammation. These pathological changes will impair the normal homeostasis and manifest clinically as respiratory dysfunction. Clinical identification of infectious agents can be challenging since respiratory signs can be unspecific varying from mild unproductive cough to severe pneumonia accompanied with systemic changes. Currently, numerous diagnostic tools are available for the identification of respiratory agents. The development of molecular diagnostic tools allows rapid identification of a 
wide variety of pathogens and establishment of more accurate treatments. ${ }^{1}$ However, diagnosis of respiratory diseases is still often based on history, clinical signs, radiography, cytology, and bacterial culture. ${ }^{2}$ Histopathology is rarely used as a diagnostic tool in practice for lower respiratory infections; however, nasal biopsies are commonly used for identification of agents affecting the upper respiratory tract. ${ }^{1}$ Due to potential complications associated with collection procedures, biopsies of the lungs for histopathology are less frequently utilized for etiological diagnosis. Instead, morphological changes are most commonly evaluated by cytology. ${ }^{3}$ Still, histopathology specimens obtained during necropsy are considered the best resource for pathogenesis studies and in situ detection of agents associated with local changes. This review discusses general and specific morphological changes, the pathogenesis, clinical signs, and treatment for some of the important viral, bacterial, fungal, and parasitic causes of infectious respiratory disease in dogs.

\section{Infectious nasal diseases Mycotic rhinitis}

Fungal rhinitis is most commonly caused by ubiquitous soil fungi, notably Aspergillus fumigatus, or rarely by Penicillium spp., in young to middle aged dolichocephalic and mesaticephalic dogs. Presenting signs include mucopurulent discharge (initially unilateral), sneezing, epistaxis, and nasal depigmentation or ulceration. Stertor and stridor are variably present and, in advanced cases, facial deformity may be appreciated with or without lacrimal duct obstruction and epiphora. ${ }^{4}$

It is not known why A. fumigatus causes disease in only a small proportion of $\operatorname{dog} s^{5}$ and whether disease results from higher exposure to fungi or from suppression of normal nasal defenses. ${ }^{6}$ Fungal organisms are cleared by the innate immune system and invasion requires adherence, penetration of the respiratory epithelium, destruction of surrounding cells, and resistance to phagocytosis. ${ }^{4}$ The lack of fungal invasion into mucosal tissues and adjacent bone argues against systemic immune dysfunction. ${ }^{5}$ A predominant T helper 1-regulated cell-mediated immune response seems to be effective at preventing systemic dissemination of the fungus; however, it is not effective at clearing infection from the nasal cavity. ${ }^{7}$ Persistent infection may be due to defects in local defense mechanisms $^{7}$ or in the local immune response. ${ }^{5,7}$ An unexplainable increase in interleukin-10 may be playing a role in local immune dysfunction. ${ }^{5}$ Interleukin-10 impairs the antifungal functions of phagocytes, secretion of proinflammatory cytokines, and protective cell-mediated immunity. ${ }^{8}$
While these functions may be beneficial during resolution of the inflammatory response after infection is cleared, ${ }^{8}$ they may be detrimental during fulminant mycotic infection. ${ }^{5}$ Invasion into bone is usually limited to the nasal turbinates, ${ }^{4}$ with subsequent destruction being caused by a combination of host immune responses and dermonecrolytic fungal toxins. ${ }^{5}$ Various virulence factors have been studied in vitro and may contribute to the disease by interfering with innate host defenses; however, their significance in the pathogenesis of canine nasal disease is not known. ${ }^{5}$

Definitive diagnosis is best achieved with direct visualization with rhinoscopy or endoscopy, followed by microscopic examination of scrapings or biopsies of fungal plaques. ${ }^{5}$ Lesions are often surrounded by hyperemic and edematous mucosa, and there is purulent exudate, caseous debris, and/or hemorrhage in the nasal cavity. ${ }^{6}$ Destruction and distortion of the nasal turbinates varies from mild to severe. Fungal plaques appear as white, dull, usually flat, and irregular masses sitting on the mucosal surface covered with mucopurulent exudate (Figure 1A). Fungal colonies sometimes form upright spherical structures, or become grayish to black and form solid sheets of material covering large portions of the nasal cavity. ${ }^{9}$ Histopathology reveals an ulcerated mucosa covered with a plaque of necrotic tissue admixed with fibrin. The underlying lamina propria is heavily infiltrated with lymphocytes and plasma cells with fewer macrophages or, in mild cases, may have mild infiltration with neutrophils. ${ }^{7}$ Fungal organisms are rarely, if ever, observed invading the mucosa. Instead, they are found in superficial necrotic plaques and free material within the nasal cavity $^{7}$ as dense accumulations of nonpigmented, septate, 3-8- $\mu \mathrm{m}$ hyphae that branch dichotomously at 45-degree angles. ${ }^{4}$

Systemic treatment with oral antifungals is not typically efficacious as a sole therapy, and medications are expensive ${ }^{5}$ and associated with side effects including hepatotoxicity, anorexia, or vomiting. ${ }^{10}$ Instead, treatment is focused on topical antifungal treatments, which may be supplemented with systemic antifungals. Localized therapy by instilling topical antifungals such as clotrimazole and enilconazole into the nasal sinuses is preferred. ${ }^{4,11}$ The distribution and retention of the antifungal therapy within the nasal cavity and sinuses varies. ${ }^{12-14}$ To prolong drug-contact time and reduce anesthetic duration, researchers have investigated using antifungal creams, instead of suspensions, into the nasal sinuses to act as a local depot of drug therapy. ${ }^{15}$ Extensive rhinoscopic debridement of the nasal cavities before drug infusion is also important in improving treatment outcome. ${ }^{16}$ 

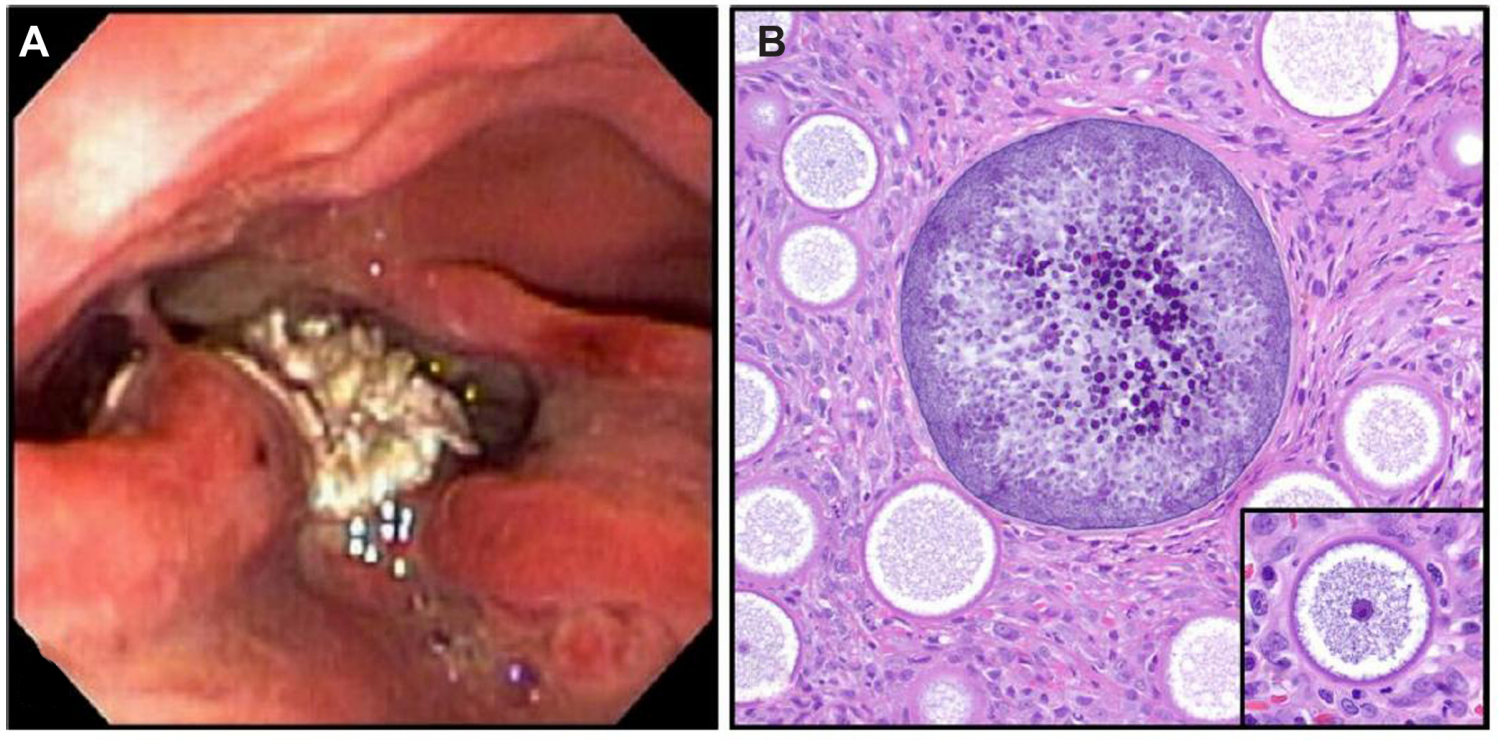

Figure I Infectious nasal diseases. (A) Nasal cavity: rhinoscopic visualization of characteristic fungal plaques in a dog with mycotic rhinitis (Aspergillus fumigatus). (B) Nasal mucosa: hematoxylin and eosin-stained photomicrograph of Rhinosporidium seeberi endospore and sporangia (inset).

Notes: The images are courtesy of (A) Dr K Sennello, Virginia-Maryland Regional College of Veterinary Medicine, Virginia Tech University (Blacksburg, VA); and (B) Dr B Porter, College of Veterinary Medicine and Biomedical Sciences, Texas A\&M University (College Station, TX).

\section{Rhinosporidiosis}

Nasal disease may rarely be caused by Rhinosporidium seeberi, an aquatic protistan parasite of the Mesomycetozoa family, which some refer to as the DRIP (Dermocystidium, the "rosette agent," Ichthyophonus, Psorospermium) clade. ${ }^{17,18}$ Development of mature endospores is stimulated by water exposure, therefore this agent is associated with wet environments. ${ }^{19}$ The parasite is endemic in India, Sri Lanka, and Argentina ${ }^{19}$ and sporadic cases have been reported in Canada, ${ }^{20}$ the United Kingdom, ${ }^{21}$ Italy, ${ }^{22}$ and the United States. The majority of cases reported in the United States are from southeastern and south central states, extending as far north as Missouri. ${ }^{23}$ Clinical signs include wheezing, sneezing, unilateral seropurulent nasal discharge, epistaxis, and possibly a visible mass within the nares. ${ }^{19}$ Exposure to contaminated water ${ }^{6}$ and history of trauma ${ }^{19,22}$ have been suggested as predisposing factors. Some authors suggest hunting and roaming dogs are at increased risk due to increased exposure to these factors. ${ }^{22}$ Animal-to-animal and animal-to-human transmission have not been documented, ${ }^{22}$ and could be explained by recent research suggesting that there are multiple host-specific strains. ${ }^{24}$

The typical lesion is a single, unilateral nasal polyp with a characteristic "strawberry" appearance that is soft, pink, and bleeds easily. ${ }^{22,25}$ Pinpoint white foci, representing mature sporangia, may be visible grossly. ${ }^{6,19}$ Nasal scrape smears are preferred over fine-needle aspiration since lesions tend to bleed, and demonstration of intact spherules with endospores free and within sporangia is diagnostic. ${ }^{25}$ However, sporangia are not often seen in cytology as they do not exfoliate readily.2. Alternatively, histopathology on excisional biopsies are both therapeutic and diagnostic and show polyploid proliferation of the submucosa, hyperplasia, and metaplasia of the overlying epithelium, granulomatous to pyogranulomatous inflammation, and sporangia in various stages of maturation (Figure 1B) ${ }^{22}$ Endospores are round, eosinophilic to magenta to basophilic bodies that are 5-15 $\mu \mathrm{m}$ in diameter with internal eosinophilic globules and thick walls. ${ }^{23}$ Stains that may be helpful in identifying endospores include toluidine blue, periodic acid-Schiff reaction, methenamine, Wright's, and Gridley's. ${ }^{19,23}$

The preferred method of treatment for nasal rhinosporidiosis is surgical excision of lesions; however, there have been reports of slowly progressive recurrence after surgery. Other treatments include systemic ketoconazole or dapsone; however, these drugs are often associated with side effects and there is limited information regarding efficacy in canine patients. ${ }^{19,22}$

\section{Nonspecific infectious rhinitis}

Nonspecific infectious rhinitis is rare in dogs and commonly occurs secondary to nasal trauma, allergy, or inhalation of foreign material. Clinical signs include sneezing, coughing, and watery-mucous to suppurative nasal discharge. Depending on the severity of infection, these signs may be accompanied by fever, lethargy, and anorexia. There are no 
specific agents associated with this clinical presentation; although, canine parainfluenza virus, canine adenovirus type 2 (CAV-2), and Bordetella bronchiseptica are the most commonly isolated agents. ${ }^{26}$ Morphological changes are nonspecific and include mucosal hyperemia and swelling from edema fluid and glandular secretions. Histologically, these changes vary upon the severity and chronicity of the disease. Initially, there is minimal ballooning degeneration of the nasal epithelium accompanied by ciliary loss, submucosal edema, and occasional infiltration of lymphocytes and plasma cells. In more severe cases with secondary bacterial invasion, the mucosa is infiltrated by neutrophils and there is necrosis and desquamation of the epithelium. In chronic stages, the lamina propria is thickened by abundant fibrous connective tissue and there is mucosal gland atrophy and epithelial dysplasia. Because predisposing factors are commonly unknown, treatments are targeted to manage nonspecific respiratory symptoms and secondary bacterial infections.

\section{Upper respiratory infections}

In dogs, respiratory infection is typically an upper airway disease referred to as laryngotracheitis, infectious tracheobronchitis (ITB), infectious respiratory disease complex, or kennel cough. The disease is highly contagious and characterized by inflammation of the upper respiratory tract. Many cases of ITB involve both viral and bacterial pathogens and numerous agents have been isolated. The most commonly identified etiologic agents include canine parainfluenza virus, CAV-2, and $B$. bronchiseptica. As secondary agents, canine herpesvirus, canine reovirus (type 1, 2, and 3), and bacteria such as Streptococcus spp., Pasteurella spp., Pseudomonas spp., coliforms, and mycoplasmas are often reported. Recently, reports have implicated the involvement of unusual agents such as Streptococcus equi subspecies zooepidemicus ${ }^{27,28}$ and/or Mycoplasma cynos, ${ }^{29,30}$ either alone or in association with predisposing viral agents as part of this multietiological complex. New viruses have also emerged as novel pathogens of the canine respiratory tract including canine influenza virus (CIV), group 1 canine coronavirus (canine pantropic coronavirus), group 2 canine coronavirus (canine respiratory coronavirus), ${ }^{26}$ and pneumovirus; ${ }^{31}$ however, the role of these pathogens as causes of ITB is still under debate.

Pathogens are normally transmitted by coughing, sneezing, or nose-to-nose contact in dogs that are densely housed (ie, in shelters, day care centers, boarding kennels, or veterinary hospitals). ${ }^{32}$ The occurrence of clinical signs is due to both high numbers of pathogens in the same densely housed environment and inadequate sanitary conditions. Important factors such as population density, ventilation, sanitation, and staff training also play a role. ${ }^{33}$ Moreover, these animal facilities have rapid animal turnover, and a high percentage of young animals may be immunocompromised due to a poor or complete lack of passive immunity. ${ }^{34}$ In animal shelters, it has been demonstrated that this disease has a different epidemiological pattern compared to dogs in households. ${ }^{33}$ Once the infection is established in a shelter, it quickly reaches high morbidity rates. Normally, clinical signs are self-limiting; however, under predisposing conditions such as overpopulation and immune deficiency, the clinical presentation might vary from severe to fatal. ${ }^{32}$

Lesions within the upper respiratory tract vary from apparently normal airways to hyperemia and mucopurulent exudate, depending on the severity of the infection and secondary bacterial involvement. Inconsistently, associated lymphoid tissue, tonsils, retropharyngeal, and tracheal lymph nodes can be moderately enlarged. Histologically, changes are confined to the trachea and bronchi, and are characterized by initial lymphoplasmacytic infiltration of the lamina propria accompanied by interstitial edema and capillary hyperemia. Necrosis of the epithelium is uncommon and secretory glands can be hyperplastic. In the most severe cases, tracheal and bronchial lumens can be occluded by abundant mucoid material intermixed with neutrophils and bacterial colonies. Histological changes are rather unspecific and histopathology is rarely used as a diagnostic technique. Moreover, the etiological diagnosis is uncommon since a large number of pathogens frequently interacts and/or overlaps. Thus, the most common diagnostic routine is based on the presence of clinical signs.

Treatment of ITB is symptomatic; however, due to the common occurrence of secondary infections with a broad spectrum of bacteria, antibiotic treatment is the first therapeutic approach. Antibiotics should be selected based on culture and sensitivity tests of airway specimens collected by transtracheal aspiration or bronchoscopy. ${ }^{35}$ The antibiotics most commonly used are amoxicillin/clavulanic acid, cephalexin, clindamycin, and azithromycin. These antibiotics can reach effective concentrations in the tracheobronchial mucosa as well as pulmonary parenchyma. When the bacterial infection is severe and animals do not respond to parenteral antibiotics, aerosolized kanamycin sulfate or gentamicin sulfate has been shown to reduce $B$. bronchiseptica numbers in the distal trachea and bronchi. ${ }^{36}$ In order to ameliorate the clinical signs of ITB, cough suppressants and bronchodilators have been recommended. ${ }^{37}$ Antitussives with codeine derivatives such as hydrocodone or butorphanol are used to control persistent 
nonproductive coughing. Even though ITB does not normally cause bronchial hyperactivity/spasm, bronchodilators such as theophylline and aminophylline may be used to prevent bronchospasm and therefore act as effective cough suppressants. Usually, clinical signs are not severe and affected dogs do not present with anorexia. However, during the acute phase or in prolonged severe cases, supportive care by maintaining adequate caloric and fluid intake may be necessary. ${ }^{36}$

There are currently vaccines for most of the agents associated with ITB. Some of the agents responsible for ITB, such as canine distemper virus and CAV-2, are included in the core vaccine. ${ }^{33}$ The main goal of core vaccines is to protect animals against life-threatening diseases that have a global distribution. However, the World Small Animal Veterinary Association has defined a core vaccine for shelter-housed dogs or those in high density populations that are exposed to different environments compared to those in households. Thus, the vaccination guidelines group of the World Small Animal Veterinary Association has defined that this core vaccine for shelter-housed dogs must include canine distemper virus, canine parvovirus type $2, \mathrm{CAV}-2$, intranasal $B$. bronchiseptica $\mathrm{Bb} 1$, and canine parainfluenza virus. ${ }^{34}$ The use of CIV is included in the recommended noncore vaccine for shelter dogs; however, the benefit of this vaccine is limited if exposure cannot be prevented for at least a week after the second immunization. ${ }^{38}$

\section{Lower respiratory disease}

While a number of viral agents have been implicated in case reports of lower respiratory disease,,$^{29,39-43}$ the bulk of clinically recognized viral pneumonia can be attributed to three viruses: canine distemper virus, canine parainfluenza virus, and CAV-2. Pure viral pneumonia is characterized by a nonspecific interstitial pattern. When the thorax is opened, the lungs fail to collapse, are diffusely red to gray, meaty, and wet. Rib impressions may be noted on the visceral pleural surface, and there is minimal visible exudate within airspaces unless a secondary bacterial pneumonia has developed. Histological changes observed during the early stages are nonspecific and mostly associated with circulatory changes: congestion and hyperemia of the small and medium-sized capillaries. As the infection progresses, these changes are characterized by thickening of the alveolar septae by interstitial edema, lymphocytes, plasma cells, and occasionally a few macrophages, and alveoli are lined with hyperplastic type II pneumocytes. Pulmonary fibrosis can occur as a result of chronic interstitial pneumonia. ${ }^{6}$ The clinical presentation of a pure viral pneumonia is rare since viral infection normally impairs pulmonary defenses, and inevitably results in secondary bacterial infections and bronchopneumonia. ${ }^{36}$ Based on the exudate observed in the later stages of disease, bacterial bronchopneumonias can be classified as suppurative or fibrinous; however, since both exudates can coexist, this morphological differentiation is rather difficult. Suppurative bronchopneumonias are histologically characterized by bronchial, bronchiolar, and alveolar lumina that are filled with numerous neutrophils, macrophages, and fibrin with occasional areas of hemorrhage. ${ }^{6}$ Treatment is targeted to managing clinical signs and secondary bacterial infections, similar to those described for ITB; however, in more severe cases dogs could need oxygen supplementation or mechanical ventilation. $^{44}$

The epidemiology and pathogenesis of specific etiologic agents is well studied and reviewed, therefore only those that are newly emerging and concerning will be mentioned because of their independent ability to produce disease with higher mortality rates than expected for typical ITB or pneumonia.

\section{Canine influenza}

CIV is considered an emerging disease and has a fairly recent history. Since the 1970s, studies confirmed that dogs could be experimentally infected with human H3N2.45 Prior to 2004, influenza was not considered a specific canine disease. Dogs were also not considered as reservoirs for influenza, because they did not maintain their influenza subtype and could not transmit influenza virus between dogs. ${ }^{46}$ In 2004, the first interspecies transmission from an equine strain was described in a greyhound population in Florida. ${ }^{47,48}$ The disease has become widespread and is currently affecting 30 states in the United States, and today is considered a major threat in dogs densely housed. After the first report in the United States, several studies demonstrated interspecies transmission in numerous countries. In the United Kingdom, serological, immunohistochemical, and molecular retrospective studies have linked outbreaks of respiratory diseases in English foxhounds with equine influenza virus. ${ }^{49}$ During an equine influenza outbreak in Australia, the presence of influenza virus in dogs in close contact with $\mathrm{H} 3 \mathrm{~N} 8$ equine influenza virus-infected horses was confirmed. ${ }^{50}$ Conversely, attempts to prove the presence of influenza in Canada showed that only one dog was serologically positive over 225 evaluated dogs presented for primary care to veterinary clinics. This dog was previously in contact with race tracks in Texas. ${ }^{51}$

Influenza A virus is composed of eight separate strands of ribonucleic acid that code for eleven proteins. The virus can 
be classified into subtypes based on two superficial antigens, the hemagglutinin and neuraminidase proteins. There are 16 different types of hemagglutinin ( $\mathrm{H} 1$ to $\mathrm{H} 16)$ and nine neuraminidase antigens (N1 to N9) ${ }^{52}$ Sequence analysis of the CIV indicates that the strain has $96 \%$ nucleotide sequence identity with $\mathrm{H} 3 \mathrm{~N} 8$ equine influenza virus. ${ }^{48}$

The first report of influenza in dogs associated with the H3N8 infection described a highly contagious respiratory disease, with high morbidity (reaching 60\%-80\%) and low mortality $(1 \%-5 \%) .{ }^{53}$ However, in the first report within the Florida greyhound population, mortality rates reached $36 \%{ }^{48} \mathrm{H} 3 \mathrm{~N} 8$ is not the only strain involved in canine infection. Serological reports from South Korea demonstrated high antibody prevalence against H3N2. ${ }^{54,55}$ Later, surveys performed in China demonstrated that the H3N2 strain observed in Korea was also responsible for sporadic cases in China. ${ }^{56}$ Additional studies revealed that respiratory disease in several kennels in South Korea was also caused by an H3N2 strain with 95\%-99\% homology to influenza strains of avian origin. ${ }^{55,57}$ The infection with H3N2 caused only mild transient respiratory disease. ${ }^{58}$ Interspecies transmission with the high pathogenicity avian influenza virus $\mathrm{H} 5 \mathrm{~N} 1$ strain has also been reported in dogs. ${ }^{59}$ In 2004, a dog with severe respiratory signs was reported in Thailand. The dog died several days after ingestion of a duck carcass from a region where an outbreak of high pathogenicity avian influenza virus H5N1 was described. ${ }^{60}$ Phylogenetic analysis revealed that the virus isolated from the dog was closely related to the high pathogenicity avian influenza virus $\mathrm{H} 5 \mathrm{~N} 1$ recovered from viruses from avian influenza outbreaks in the same period. ${ }^{60}$ Despite numerous studies demonstrating that dogs have the epithelial receptor necessary for viral attachment in the upper and lower respiratory tract, ${ }^{61} \mathrm{H} 5 \mathrm{~N} 1$ dog-to-dog transmission could not be demonstrated in contact animals. ${ }^{62}$ Unlike H5N1 influenza virus, canine-adapted H3N2 influenza virus is capable of dog-to-dog and dog-to-cat transmission and causes respiratory disease in both species. ${ }^{63,64}$

Two clinical presentations have been described in dogs with CIV infection. A milder, transient respiratory disease is the most common presentation and resembles ITB. The disease is characterized initially by fever, followed by sneezing, ocular discharge, cough, and purulent nasal discharge that resolves 10-14 days after infection. ${ }^{65}$ The peracute and fatal - presentation is characterized mainly by severe pulmonary, pleural, and mediastinal hemorrhage, and may be the result of a secondary bacterial infection. ${ }^{66}$ The histological changes that normally accompany CIV infection are rather nonspecific and vary from mild tracheitis, bronchitis, and bronchiolitis to suppurative bronchopneumonia. ${ }^{67}$ Nevertheless, these lesions are insufficient to make a specific diagnosis and require complementary diagnosis such as viral isolation, polymerase chain reaction, immunohistochemistry, and serology. ${ }^{68}$

The pathogenesis of CIV does not vary significantly from other influenza subtypes affecting mammals. The virus replicates in the epithelial cells of the upper and lower respiratory tract causing epithelial necrosis, followed by neutrophilic infiltration and later infiltration of airways with mononuclear inflammatory cells. In later stages, there is type II alveolar hyperplasia. ${ }^{68}$ Alveolar macrophages are responsible for production of tumor necrosis factor- $\alpha$ and other important proinflammatory cytokines (interleukin-1 and interleukin-8), which establish the acute inflammatory response and appearance of clinical signs. ${ }^{58}$ Although it is not clear if the pulmonary source of interleukin-10 is T lymphocytes or macrophages, there is experimental evidence that this cytokine plays an important role in increasing susceptibility to bacterial pneumonia following influenza infection. ${ }^{69}$

There is no specific treatment for CIV infection. Antibiotics are important for treating the secondary bacterial infections that are commonly associated with H3N8 CIV infections. A recombinant equine herpesvirus-1 vaccine expressing the hemagglutinin of equine $\mathrm{H} 3 \mathrm{~N} 8$ has been shown to reduce clinical signs and virus shedding in dogs challenged with a recent isolate of $\mathrm{CIV}^{70}{ }^{70} \mathrm{~A}$ commercial vaccine against CIV subtype H3N8 was conditionally approved by the United States Department of Agriculture in 2009 and fully licensed in June 2010. ${ }^{38,71}$ This inactivated vaccine has proven to control CIV clinical signs and reduce the severity of associated pulmonary lesions as well as viral shedding. In a coinfection trial with $S$. equi subspecies zooepidemicus, the vaccine significantly reduced clinical signs. ${ }^{72}$ Given that the risk profile necessary for CIV infection is similar to that of dogs exposed to kennel cough, this vaccine may be useful in those dogs vaccinated against B. bronchiseptical parainfluenza. ${ }^{65}$

\section{Canine coronavirus}

Canine respiratory coronavirus was first detected in the United Kingdom in 2003 from the trachea and lung tissues of dogs. ${ }^{73}$ This virus is closely related to human and bovine coronaviruses and distinct from canine enteric coronavirus. This respiratory coronavirus is widespread in North America, Japan, and several European countries; the seroprevalence varies from $54.7 \%$ in the United States to $17.8 \%$ in Japan. ${ }^{73,74}$ Canine respiratory coronavirus has been associated with respiratory 
disease, particularly in kenneled dog populations. ${ }^{75}$ This virus has been detected by reverse transcriptase-polymerase chain reaction in asymptomatic and symptomatic dogs that suffered from mild or moderate respiratory disease. ${ }^{76}$ The role of canine respiratory coronavirus in ITB is not clear and it is likely that infection with this virus only induces subclinical or mild respiratory disease. Coronavirus has been associated with upper respiratory disease but is also capable of damaging the respiratory epithelium and predisposing to bacterial infection. ${ }^{26}$ Canine pantropic coronavirus was first described in Italy and now several fatal outbreaks have been reported around Europe. ${ }^{74}$ These outbreaks were characterized by high mortality in young animals. Several organs including the gastrointestinal tract, nervous system, and respiratory system were affected. Postmortem examination showed extensive lobar bronchopneumonia compromising the cranial and caudal lobes, along with effusions in the thoracic cavity. ${ }^{76}$ Viral isolation and further characterization revealed the presence of coronavirus type 2 that contains a point mutation, which changes the cellular tropism of this virus. There is no current vaccine, and there is no cross protection with gastrointestinal coronavirus. $^{77}$

\section{Streptococcus spp.}

Streptococcus spp. are opportunistic pathogens of the upper respiratory tract. S. equi subspecies zooepidemicus is an important pathogen of horses and pigs but has recently been linked to cases of acute fatal pneumonia in dogs in several countries. ${ }^{28}$ Numerous reports describe outbreaks of acute, hemorrhagic pneumonia characterized by high morbidity up to $100 \%$ and very high mortality reaching $50 \%-60 \%$. $^{78}$ Currently there is insufficient data to determine the pathogenesis of $S$. equi subspecies zooepidemicus in dogs. However, several factors such as host susceptibility, coinfections, and presence of three superantigen genes ( $s z e F, s z e N$, and szeP) have been proposed as contributors to the rapid onset of disease and fast deterioration of many dogs infected with $S$. equi subspecies zooepidemicus. ${ }^{27}$ High levels of proinflammatory cytokines (tumor necrosis factor- $\alpha$, interleukin- 6 , and interleukin-8) observed during the acute infection suggest that the pulmonary lesions are the result of a "cytokine storm" and acute respiratory distress syndrome. ${ }^{79}$

Pneumonic lesions appear within 24 hours postinfection and are characterized by rubbery, mottled, dark to bright red lungs accompanied by severe hemothorax and areas of collapse ${ }^{80}$ In a single study from the United Kingdom, different pneumonic patterns were observed: fibrinosuppurative, necrotizing, and hemorrhagic $(65.4 \%)$, fibrinous $(15.4 \%)$, hemorrhagic (15.4\%), and fibrinosuppurative (3.8\%). ${ }^{79}$ Common histopathologic findings include severe suppurative and hemorrhagic bronchopneumonia characterized by diffuse alveolar neutrophilic infiltration, abundant hemorrhage and edema, and large chains or colonies of gram positive bacteria. Occasionally, pulmonary lesions are accompanied by necrosuppurative bronchitis and tracheitis. ${ }^{78}$

Due to the acuteness and severity of clinical signs, intravenous antibiotics are the treatment of choice. Clinical isolates seem to be sensitive to the following antimicrobial agents: cefalotin, amoxicillin/clavulanic acid, tetracycline, trimethoprim/sulfadiazine, enrofloxacin, marbofloxacin, and penicillin G. Antibiotic sensitivity profiles have become a very important issue, since humans can acquire the infection from canine cases. ${ }^{81}$

\section{Fungal pneumonia}

Fungal infection may manifest as primary pneumonia or systemic disease with dissemination to the lung and other organs. Clinical signs of lower respiratory tract infection include coughing, tachypnea, dyspnea, and exercise intolerance. Additionally, if there is dissemination, there may be other reported clinical manifestations referable to affected organ systems. ${ }^{82}$ Blastomyces dermatitidis, Histoplasma capsulatum, and Coccidioides immitis are the primary fungal pathogens involved in canine pneumonia. ${ }^{82}$

$B$. dermatitidis exists as a mold (saprophytic phase) in sandy, acidic soils near water ${ }^{83}$ characterized by hyphae that produce conidiophores with spherical or oval conidia ${ }^{84}$ The fungus is endemic in basins of the Mississippi, Ohio, and St Lawrence rivers in North America ${ }^{6}$ and also found in Canada, Africa, and India. ${ }^{85}$ Dogs at higher risk of infection are highly involved in outdoor activities and often include 2-4 year olds, male intact, and medium to heavy weight hound or sporting dogs. ${ }^{86,87}$ Spores produced by mycelial growth are inhaled and enter terminal airways ${ }^{83}$ where they transform into a yeast (parasitic phase), which reproduces by broad-based single buds ${ }^{84} \mathrm{~B}$. dermatitidis quickly disseminates to other organs through vascular and lymphatic vessels, and in some cases, lung lesions have resolved by the time clinical signs referable to other affected organs arise. $^{83}$

H. capsulatum is a dimorphic fungus that exists as a mold (saprophytic phase) at temperatures of $25^{\circ} \mathrm{C}-30^{\circ} \mathrm{C}$ characterized by septate hyphae with microconidia and macroconidia. ${ }^{84}$ The fungus is endemic in temperate and subtropical regions, with most cases in the United States occurring in river valleys of the Ohio, Missouri, and Mississippi rivers. ${ }^{88}$ The infective 
fungal particles, microconidia and macroconidia, are inhaled and deposited in the lower respiratory tract where they transform into yeast (parasitic phase). ${ }^{84,88,89}$ Virulence factors of $H$. capsulatum allow the organism to enter and survive within phagocytes and subsequently disseminate to monocyte-rich organs early in the course of disease. ${ }^{84,88,90}$

C. immitis is a mold in soil (saprophytic phase) made up of hyphae with secondary branches and chains of infectious arthroconidia. The regional distribution of this fungus is primarily in the Lower Sonoran life zone, which includes areas of southwestern United States (Arizona, Utah, New Mexico, Nevada, and Texas), Mexico, and Central and South America. ${ }^{82,84,91}$ In tissue (parasitic phase), the arthroconidia grow into spherical sporangia ("spherules"), which produce hundreds of endospores. ${ }^{84}$ Veterinarians within an endemic region reported that clinical illness seems to occur most commonly in young adult dogs. Additionally, dogs that spent more time outdoors, had more land to roam, and were exposed to more dusty environments in endemic areas were at increased risk of infection. ${ }^{92}$ Dissemination can occur to nearly any tissue creating a wide range of clinical signs outside the respiratory tract. In dogs with chronic complaints of respiratory disease, lameness, and/or neurologic signs that also have a travel history to endemic areas within the past 3 years, C. immitis infection should be suspected. ${ }^{93}$

Clinical signs, history, physical examination, and imaging lead to a strong clinical suspicion of mycotic disease; however, because treatment is expensive and sometimes cause side effects, a definitive diagnosis through identification of the organism is often warranted. When performed together, cytology, histopathology, and culture approach a specificity of nearly $100 \%$ depending on the expertise of the pathologist and laboratory. ${ }^{94}$ Diagnosis can often be made with cytologic examination of transtracheal wash or bronchoalveolar lavage fluids or fine-needle aspiration of parenchymal lesions. ${ }^{86,93,95-99}$ Because the organisms are located within the interstitium, bronchoalveolar lavage is more likely to recover the organisms for identification; ${ }^{86,96,99}$ although, transtracheal wash is a less invasive and safer procedure. ${ }^{99}$ Regardless of the etiology, the lung typically contains multiple, tan-gray, variably sized nodules scattered throughout. In blastomycosis, the nodules contain pyogranulomas or granulomas that occasionally contain extensive central caseous necrosis with a thin rim of macrophages. The number of intralesional yeast bodies is variable within extensive inflammation and often missed in routine hematoxylin and eosin stains, particularly if antifungal therapy or partial immunity was initiated. ${ }^{6}$ The yeast is round, 5-15 $\mu \mathrm{m}$ in diameter, has a distinct double-contoured wall that is about $1-\mu \mathrm{m}$ thick, and granular protoplasm that completely or partly fills the center, and occasionally displays single broad-based budding (Figure 2A). ${ }^{6}$ Rarely, filamentous and pseudohyphal forms with conidia have been identified. ${ }^{83}$ In histoplasmosis, the nodules are characterized microscopically by granulomatous inflammation containing epithelioid macrophages, many
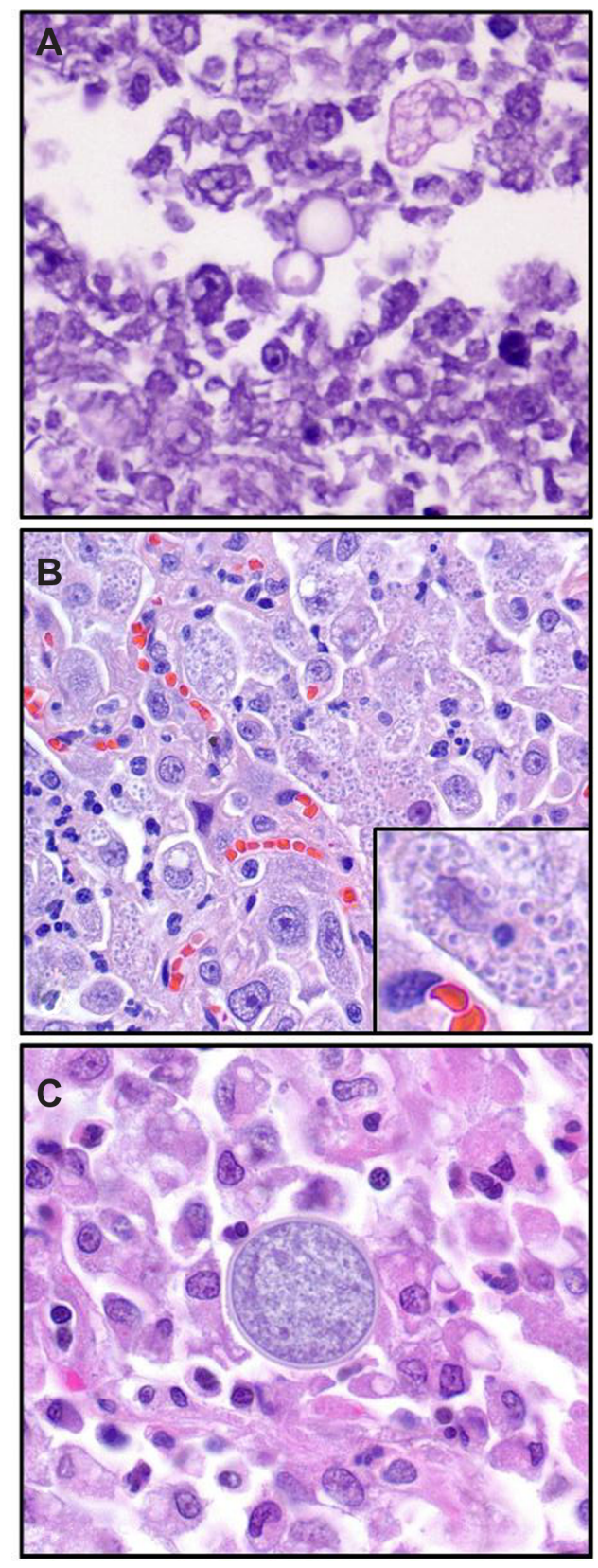

Figure 2 Etiologic agents of fungal pneumonia in the lung stained with hematoxylin and eosin. (A) Broad-based budding yeast form of Blastomyces dermatitidis. (B) Numerous Histoplasma capsulatum organisms packed within the cytoplasm of macrophages (inset). (C) Intralesional yeast form of Coccidioides immitis.

Note: The images are courtesy of (A) Dr P Piñeyro, nVirginia-Maryland Regional College of Veterinary Medicine, Virginia Tech University (Blacksburg, VA); and (B and C) Dr B Porter, College of Veterinary Medicine and Biomedical Sciences, Texas A\&M University (College Station, TX). 
containing numerous $H$. capsulatum organisms, multinucleated giant cells, and fewer neutrophils, plasma cells, and lymphocytes. ${ }^{88} H$. capsulatum organisms are numerous, intracellular, 2-4 $\mu \mathrm{m}$ in diameter, and have round bodies with a basophilic center and light halo with occasional narrow-based budding (Figure 2B). Organisms are often identified within macrophages and sometimes neutrophils in rectal scrapings, imprints of colonic biopsies ${ }^{88}$ peritoneal and pleural effusions, ${ }^{100,101}$ and rarely in cerebrospinal fluid. ${ }^{102}$ Rarely, $H$. capsulatum has been identified in circulating neutrophils and eosinophils. ${ }^{103,104}$ In coccidioidomycosis, the initial reaction is primarily suppurative, then the lesion develops into a pyogranuloma or granuloma characterized by epithelioid macrophages, a few giant cells, lymphocytes, and neutrophils. ${ }^{6}$ Spherules are large, 10-80 $\mu \mathrm{m}$, round, double-walled structures (Figure 2C) containing numerous endospores, and may be numerous within microabscesses ${ }^{91}$ or lesions with prominent suppuration. However, in chronic cases where there is little neutrophilic inflammation, few organisms are present and may be found engulfed in giant cells. ${ }^{6}$ In all cases, periodic acid-Schiff, Gridley's fungal, or Gomori's methenamine stains may be needed to help identify the organisms. ${ }^{6,83}$

Treatment of fungal pneumonia mainly involves the use of azole drugs (itraconazole, ketoconazole, or fluconazole) and/or amphotericin B. ${ }^{83,88,91,105}$ Itraconazole is preferred for the treatment of $B$. dermatitidis $s^{83,106}$ and $H$. capsulatum infections. ${ }^{88}$ In general, itraconazole treatment in B. dermatitidis patients should be administered for at least 60 days and for at least 1 month after resolution of clinical signs. ${ }^{83}$ For H. capsulatum, 4-6 months of treatment with itraconazole is usually sufficient and higher initial loading doses may be required in those with severe clinical signs. ${ }^{88}$ While itraconazole treatment is expensive, it is easier to administer and causes fewer side effects compared to amphotericin B. ${ }^{106}$ In hopes of lowering treatment costs, one study compared fluconazole and itraconazole, and found similar efficacies; however, fluconazole often required a longer treatment period to obtain clinical remission. ${ }^{107}$ Fluconazole is sometimes used in cases with ocular or central nervous system involvement because of its excellent water solubility allowing for penetration through blood-brain and blood-ocular barriers. ${ }^{86}$ Although ketoconazole is a cheaper drug, side effects are more commonly reported. ${ }^{88}$ Ketoconazole is the drug of choice in $C$. immitis infections, and the required length of administration may extend to at least 1 year in those with disseminated disease or bone involvement. ${ }^{91,108}$ Amphotericin B is used in conjunction with azole therapy in cases with severe or fulminating pulmonary or gastrointestinal disease associated with $H$. capsulatum infection, or in refractory cases because of its rapid onset of action. ${ }^{86,88}$ Administration is intravenous only, and there is a risk of nephrotoxicity. ${ }^{83}$ Using a lower cumulative dose of amphotericin $\mathrm{B}$ followed by a 60 -day course of ketoconazole ${ }^{109}$ or the use of an amphotericin B lipid complex, which is one-tenth as toxic as traditional amphotericin $\mathrm{B},{ }^{110}$ have been reported to be safer and effective alternatives. Newer drugs that are being investigated for treatment of fungal infections include chitin synthase inhibitors (nikkomycin Z and caspofungin), terbinafine (a naftifine analog), and newer azoles (voriconazole and posaconazole). ${ }^{91}$ Some advocate the additional use of anti-inflammatory doses of glucocorticoids in order to decrease secondary inflammation associated with the death of fungal organisms ${ }^{105}$ or to reduce airway obstruction from hilar lymphadenopathy in chronic cases. ${ }^{111}$ However, a clear benefit is not always appreciated ${ }^{95}$ and some do not recommend it in order to avoid dissemination. ${ }^{103,104}$

\section{Parasitic respiratory diseases Metastrongyloid nematodes}

There are four metastrongyloid nematodes that cause respiratory disease in dogs: Oslerus osleri, Crenosoma vulpis, Filaroides hirthi, and Filaroides (Andersonstrongylus) milksi. ${ }^{105,112,113}$ The prevalence of lungworm infections is presumed to be low, based on a few fecal examination studies; however, this diagnostic technique bears limitations that may underestimate the number of true cases. ${ }^{113}$

O. osleri inhabits the distal trachea, tracheal bifurcation, and first-division bronchi within granulomatous nodules on the mucosal surface. ${ }^{112}$ The life cycle is direct with transmission occurring through the saliva from the dam to pups during maternal grooming or regurgitation of food, ${ }^{114}$ or from ingestion of contaminated feces. ${ }^{113}$ Infections may be subclinical or cause chronic cough that is sometimes exacerbated with exercise ${ }^{113}$ or tracheal palpation. ${ }^{114}$ Uncommonly, infections may present as acute dyspnea or as subacute disease characterized by intermittent difficulties in breathing with no coughing. ${ }^{115}$ Visualization of raised nodules at and near the tracheal bifurcation by bronchoscopy (Figure 3A), in addition to recovery of first-stage larvae in bronchial mucus or feces provides a definitive diagnosis. ${ }^{113-116}$ Nodules contain coiled adults within spaces - often dilated lymphatics - surrounded by loose connective tissue and marked inflammation composed of plasma cells, neutrophils, and eosinophils (Figure 3B). Some spaces containing worms are open to the airway lumen and intraluminal protrusion of 

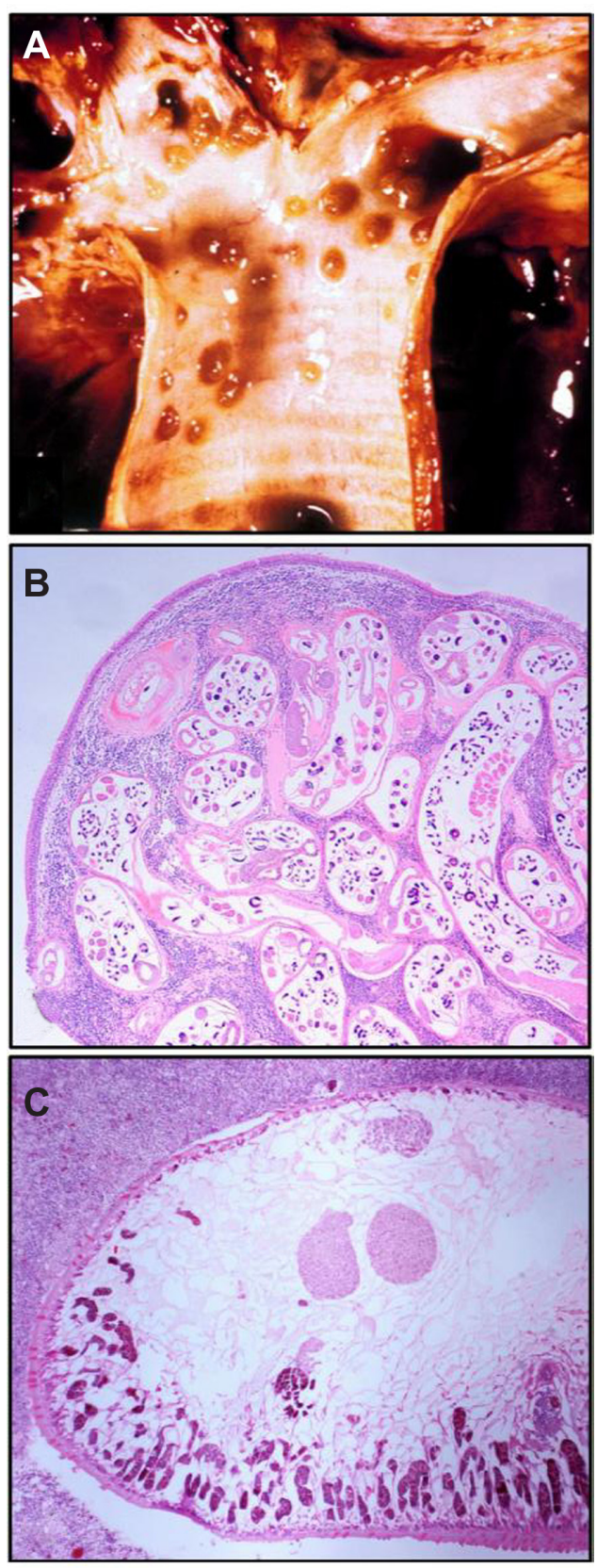

Figure 3 Etiologic agents of parasitic respiratory diseases. (A) Trachea: multiple raised nodules at the tracheal bifurcation. (B) Trachea: hematoxylin and eosinstained photomicrograph of numerous intralesional Oslerus osleri nematodes within the submucosa. (C) Lung: hematoxylin and eosin-stained photomicrograph of Paragonimus kellicotti within a focus of inflammation.

Notes: The images are courtesy of (A) Dr G Saunders, Virginia-Maryland Regional College of Veterinary Medicine, Virginia Tech University (Blacksburg, VA); (B) Dr B Porter, College of Veterinary Medicine and Biomedical Sciences, Texas A\&M University (College Station, TX); and (C) Dr T Leroith, Virginia-Maryland Regional College of Veterinary Medicine, Virginia Tech University (Blacksburg, VA).

the tail of female worms is sometimes evident. ${ }^{117}$ Successful therapy for $O$. osleri is based on cessation of larval output, resolution of clinical signs, and clearance of tracheal and bronchial nodules. ${ }^{118}$ Successful reported treatments have included extended, oral administration of benzimidazoles (fenbendazole, thiabendazole, oxfendazole), or off-label use of macrocyclic lactones (ivermectin and doramectin), subcutaneously. ${ }^{114-116,118,119}$ Surgery to debulk large, obstructive masses may be considered; however, it is usually not necessary as nodules will regress with medical therapy. ${ }^{115}$

C. vulpis also inhabits the trachea, bronchi, and bronchioles causing a chronic bronchitis-bronchiolitis characterized by a chronic cough. ${ }^{113}$ Wild canids, such as foxes and coyotes, and domestic canids serve as definitive hosts. First-stage larvae are passed in the feces after being coughed up and swallowed, and subsequently infect terrestrial snails or slugs, which serve as intermediate hosts. Infection is then acquired after ingestion of the intermediate hosts. ${ }^{113,120}$ Definitive diagnosis is based on detection of first-stage larvae in feces or transtracheal wash samples. ${ }^{13,120,121}$ In comparison to O. osleri, C. vulpis is found more often within the bronchi, endoscopically, and accompanied by erythema, mucoid discharge, or hyperplastic nodules. ${ }^{115}$ Successful treatment has been commonly achieved with oral fenbendazole; ${ }^{120-123}$ however, administration of febantel, milbemycin oxime, levamisole, and diethylcarbamazine have also been used. ${ }^{113,120,124}$

F. hirthi and F. milksi are very similar and parasitize the alveoli and terminal airways causing multifocal interstitial pneumonitis. ${ }^{112}$ The life cycle of $F$. milksi is unknown, and the transmission of $F$. hirthi is through ingestion of firststage larvae in feces (coprophagy). ${ }^{113}$ Infections are usually subclinical; however, some dogs - especially those that are immunosuppressed - may present with acute or chronic coughing and dyspnea. ${ }^{105,112}$ Definitive diagnosis is made by detection of first-stage larvae in bronchial mucus or feces. ${ }^{113,125-127}$ Findings at necropsy are generally considered incidental and include widely scattered, subpleural, gray-tan or black-green, 1-5-mm diameter nodules, which may have clear cystic centers or be white and firm. Microscopically, larvae typically incite an acute suppurative response. There is very little response to living worms within the alveoli; however, when worms are dead or degenerating, there is marked granulomatous and eosinophilic inflammation. After worm fragments have been cleared, there may be residual foci of granulomatous interstitial pneumonia. ${ }^{6}$ Differentiation between $F$. hirthi and F. milksi is not possible in histopathologic sections. ${ }^{113}$ Treatments for F. hirthi include oral administration of fenbendazole, ${ }^{125-127} 5$ days of oral albendazole, which is repeated 3 weeks later, ${ }^{105}$ or subcutaneous ivermectin. ${ }^{113}$

\section{Capillaria aerophila (Eucoleus aerophilus)}

A relatively uncommon cause of respiratory disease in dogs is cause by a trichurid nematode, $C$. aerophila. Sporadic cases 
have been reported in the United States, Canada, ${ }^{128}$ and various countries in Europe. Recent interest has grown due to zoonotic potential and a potentially expanding distribution in Europe that has been speculated to be due to global warming. ${ }^{129-131}$ The life cycle is direct and ova are produced from the adults in the bronchi, coughed up, swallowed, and passed in the feces. ${ }^{105,112}$ The ova require approximately 30-45 days to mature after excretion and can remain viable in the soil for up to a year. ${ }^{12,129,130}$ Ova may also mature within earthworms, which act as facultative intermediate hosts; although, the importance in transmission is not fully elucidated. ${ }^{129,130}$ Most infections are subclinical, but some dogs may present with chronic cough. More severe signs of dyspnea, weight loss, or secondary bacterial pneumonia rarely occur. ${ }^{105,112,113,131}$ Diagnosis is based on identification of double-operculated yellow-brown ova in fecal examinations or cytologic evaluation of airway specimens. ${ }^{112,113}$ Differentiation of C. aerophila ova from those of Trichuris vulpis is important and based on the smaller size, asymmetric bipolar plugs, and anastomosing network of ridges within the wall. ${ }^{130}$ The worms are slender, 2-3 cm long, and reside as white, coiled masses embedded in the tracheobronchial mucosa, and incite a mild catarrhal bronchitis. ${ }^{6,105,112}$ Occasionally, there are embryonated eggs associated with the worms. ${ }^{6}$ Research and reports on treatment is very limited; however, fenbendazole has been reported to be successful. ${ }^{128}$

\section{Paragonimus kellicotti}

Paragonimiasis is an uncommon disease that is caused by a trematode (fluke) infestation in the lungs of dogs and other mammals. There are over 40 species of Paragonimus that have been described worldwide ${ }^{132}$ and are endemic in Asia, the Americas, and Africa. ${ }^{133,134}$ Two important species include $P$. westermani, which is the most widely distributed species, ${ }^{134,135}$ and P. kellicotti, which is endemic in North America. ${ }^{105,112,132,134}$ The life cycle is indirect and requires two intermediate hosts. Eggs passed in the feces of definitive mammalian hosts hatch into miracidium and infect aquatic snails, the first intermediate host. After development in the snail, the parasite then infects the second intermediate host, crayfish, by direct penetration or ingestion of the snail. Infection in dogs is acquired after ingesting the crayfish, followed by migration of the parasite from the intestine to the lungs where it resides, in pairs, within a fibrous subpleural cyst or bulla that communicates with bronchioles. The adults then produce ova that are coughed up, swallowed, and passed through the feces to complete the lifecycle. ${ }^{105,112,113,132-134}$ Clinical signs are often limited to chronic cough and exercise intolerance; however, severe dyspnea may occur with cyst rupture and pneumothorax. ${ }^{105,112,113,133}$

Definitive diagnosis is based on identification of characteristic eggs in bronchial mucus, feces, ${ }^{113}$ or fine-needle aspiration of lung nodules. ${ }^{136}$ These nodules may be seen radiographically as early as $2-3$ weeks postinfection ${ }^{137}$ or by computed tomography examination 30-180 days postinfection. ${ }^{135}$ The eggs are typically oval, yellow-brown, and operculated with a thickened ridge in the shell wall along the line of the operculum. ${ }^{113,136}$ Postmortem examination reveals spherical, 1-3-cm diameter, soft, dark red-brown nodules within the caudal lung lobes that contain one or two flukes and thick brown fluid. ${ }^{133}$ Microscopically, the cavitations contain marked eosinophilic and granulomatous inflammation, hemorrhage with numerous hemosiderinladen macrophages, adult flukes, and a fibrous capsule (Figure 3C). In patent infections, there are also numerous ova within lesions. As the cavitations mature, they become true cysts that are incorporated into the bronchiolar tree and lined with cuboidal epithelium. The bronchioles may contain ova and eosinophilic exudate. Additionally, hyperplasia of the peribronchiolar glands and smooth muscle, and variable chronic catarrhal eosinophilic bronchiolitis, granulomatous pleuritis, and pleural lymphangitis occur. ${ }^{6}$

Effective treatments for $P$. kellicotti in dogs have included oral administration of praziquantel, ${ }^{138,139}$ fenbendazole, ${ }^{136,140}$ or albendazole. ${ }^{118}$

\section{Pneumocystosis}

The exact taxonomic classification of Pneumocystis carinii is debated and has characteristics consistent with fungi and protozoan. ${ }^{141}$ The recognized structural forms of the organism are the cyst, with intracystic sporozoites, and the trophozoite. The cyst is thick-walled, spherical to ovoid to crescent-shaped, 4-8 um in diameter, and contains up to eight pleomorphic sporozoites. The trophozoite is thinwalled, 1-4 um in diameter, and appears to be an extracystic form of the sporozoite. ${ }^{84,141,142}$ Clinical cases of pneumonia caused by $P$. carinii in dogs are attributed to suspected or documented concurrent cell-mediated immunodeficiency or preexisting pulmonary disease. ${ }^{105,141}$ Sporadic cases and clinical disease have been reported associated with stress, crowding, immunosuppressive therapy (glucocorticoids, chemotherapy, and irradiation), and concurrently with canine distemper infection. ${ }^{141}$

Definitive diagnosis is based on direct visualization of organisms from respiratory fluids or biopsy specimens, ${ }^{143,144}$ or from amplification of DNA in samples from the lower 
respiratory tract. ${ }^{143}$ Grossly, the lungs are firm, consolidated, and pale brown or gray and do not collapse upon opening the thoracic cavity. Microscopically, alveoli are filled with aggregates of amorphous, foamy, eosinophilic material and a few macrophages and detached alveolar lining cells. ${ }^{141}$ Grocott's methenamine silver stain is often used to help identify the cyst stages of the organisms. ${ }^{144}$ Neutrophils are absent and there is little to no phagocytosis of intact organisms. Alveolar septa may be thickened with dense accumulations of plasma cells, lymphocytes, and macrophages or fibrosis in chronic infections. ${ }^{141}$

Pentamide isethionate or the combination of trimethoprim and sulfonamide has been used for successful treatment of pneumocystosis. ${ }^{105,141}$ Other drugs that have been used include carbutamide, trimetrexate, and combinations of clindamycin, primaquine, dapsone, and trimethoprim. Symptomatic therapy is often concurrently initiated and includes oxygen administration, mucolytics, bronchodilators, nebulization, and discontinuation of immunosuppressive medications. ${ }^{145}$

\section{Conclusion}

While modern vaccination and management strategies have decreased respiratory diseases in domestic dogs within households, respiratory infections are still a major concern in high density housing situations and in areas where vaccination and proper animal management and husbandry practices are not implemented. These situations allow these infections to persist, propagate, and potentially spread to other populations. Research of the classic respiratory conditions in dogs, discussed herein, has enabled the development of treatments, diagnostics, and preventative strategies for these infections. However, there are still many unanswered questions regarding the pathogenesis, immunopathology, and characteristics of the infectious agents which may provide information pertinent to the development of more specific treatments, definitive diagnostics, and preventative strategies.

\section{Disclosure}

The authors report no conflicts of interest in this work.

\section{References}

1. Windsor RC, Johnson LR, Sykes JE, Drazenovich TL, Leutenegger CM, de Cock HEV. Molecular detection of microbes in nasal tissue of dogs with idiopathic lymphoplasmacytic rhinitis. J Vet Intern Med. 2006;20(2):250-256.

2. Kogan DA, Johnson LR, Sturges BK, Jandrey KE, Pollard RE. Etiology and clinical outcome in dogs with aspiration pneumonia: 88 cases (2004-2006). J Am Vet Med Assoc. 2008;233(11):1748-1755.

3. DeBerry JD, Norris CR, Samii VF, Griffey SM, Almy FS. Correlation between fine-needle aspiration cytopathology and histopathology of the lung in dogs and cats. J Am Anim Hosp Assoc. 2002;38(4):327-336.
4. Mathews KG, Sharp NJ. Canine nasal aspergillosis-penicillosis. In: Greene CE, editor. Infectious Diseases of the Dog and Cat. 3rd ed. St Louis MO: Saunders Elsevier; 2006:613-620.

5. Peeters D, Clercx C. Update on canine sinonasal aspergillosis. Vet Clin North Am Small Anim Pract. 2007;37(5):901-916.

6. Caswell JL, Williams KJ. Infectious diseases of the respiratory system. In: Maxie MG, editor. Jubb, Kennedy, and Palmer's Pathology of Domestic Animals: Volume 2. 5th ed. Philadelphia, PA: WB Saunders; 2007:635-653.

7. Peeters D, Day MJ, Clercx C. An immunohistochemical study of canine nasal aspergillosis. J Comp Pathol. 2005;132(4):283-288.

8. Romani L. Immunity to fungal infections. Nat Rev Immunol. 2004; $4(1): 1-23$.

9. McCarthy TC, McDermaid SL. Rhinoscopy. Vet Clin North Am Small Anim Pract. 1990;20(5):1265-1290.

10. Legendre A. Antimycotic drug therapy. In: Bonagura JD, Kirk RW, editors. Kirk's Current Veterinary Therapy XII: Small Animal Practice. Philadelphia, PA: WB Saunders; 1995:327-331.

11. Sharp NJ, Sullivan M, Harvey CE, Webb T. Treatment of canine nasal aspergillosis with enilconazole. J Vet Intern Med. 1993;7(1):40-43.

12. Mathews KG, Koblik PD, Richardson EF, Davidson AP, Pappagianis D. Computed tomographic assessment of noninvasive intranasal infusions in dogs with fungal rhinitis. Vet Surg. 1996;25(4):309-319.

13. Sharman M, Lenard Z, Hosgood G, Mansfield C. Clotrimazole and enilconazole distribution within the frontal sinuses and nasal cavity of nine dogs with sinonasal aspergillosis. J Small Anim Pract. 2012;53(3): 161-167.

14. Richardson EF, Mathews KG. Distribution of topical agents in the frontal sinuses and nasal cavity of dogs: comparison between current protocols for treatment of nasal aspergillosis and a new noninvasive technique. Vet Surg. 1995;24(6):476-483.

15. Sissener TR, Bacon NJ, Friend E, Anderson DM, White RA. Combined clotrimazole irrigation and depot therapy for canine nasal aspergillosis. J Small Anim Pract. 2006;47(6):312-315.

16. Zonderland JL, Stork CK, Saunders JH, Hamaide AJ, Balligand MH, Clercx CM. Intranasal infusion of enilconazole for treatment of sinonasal aspergillosis in dogs. J Am Vet Med Assoc. 2002;221(10):1421-1425.

17. Herr RA, Ajello L, Taylor JW, Arseculeratne SN, Mendoza L. Phylogenetic analysis of Rhinosporidium seeberi's $18 \mathrm{~S}$ small-subunit ribosomal DNA groups this pathogen among members of the protoctistan Mesomycetozoa clade. J Clin Microbiol. 1999;37(9):2750-2754.

18. Fredricks DN, Jolley JA, Lepp PW, Kosek JC, Relman DA. Rhinosporidium seeberi: a human pathogen from a novel group of aquatic protistan parasites. Emerg Infect Dis. 2000;6(3):273-282.

19. Castellano MC, Breitschwerdt EB. Rhinosporidiosis. In: Greene CE, editor. Infectious Diseases of the Dog and Cat. 3rd ed. St Louis MO: Saunders Elsevier; 2006:793-795.

20. Hoff B, Hall DA. Rhinosporidiosis in a dog. Can Vet J. 1986;27(6): 231-232.

21. Miller RI, Baylis R. Rhinosporidiosis in a dog native to the UK. Vet Rec. 2009;164(7):210.

22. Caniatti M, Roccabianca P, Scanziani E, et al. Nasal rhinosporidiosis in dogs: four cases from Europe and a review of the literature. Vet Rec. 1998;142(13):334-338.

23. Hill SA, Sharkey LC, Hardy RM, Wilke VL, Smith MA, Anderson GM. Nasal rhinosporidiosis in two dogs native to the upper Mississippi river valley region. J Am Anim Hosp Assoc. 2010;46(2):127-131.

24. Silva V, Pereira CN, Ajello L, Mendoza L. Molecular evidence for multiple host-specific strains in the genus Rhinosporidium. J Clin Microbiol. 2005;43(4):1865-1868.

25. Choudhury M. Rhinosporidium seeberi in nasal smears. Diagn Cytopathol. 2011;39(8):593-594.

26. Mochizuki M, Yachi A, Ohshima T, Ohuchi A, Ishida T. Etiologic study of upper respiratory infections of household dogs. J Vet Med Sci. 2008;70(6):563-569.

27. Priestnall S, Erles K. Streptococcus zooepidemicus: an emerging canine pathogen. Vet J. 2011;188(2):142-148. 
28. Chalker VJ, Brooks HW, Brownlie J. The association of Streptococcus equi subsp. zooepidemicus with canine infectious respiratory disease. Vet Microbiol. 2003;95(1-2):149-156.

29. Chvala S, Benetka V, Mostl K, Zeugswetter F, Spergser J, Weissenbock H. Simultaneous canine distemper virus, canine adenovirus type 2, and Mycoplasma cynos infection in a dog with pneumonia. Vet Pathol. 2007;44(4):508-512.

30. Mannering SA, McAuliffe L, Lawes JR, Erles K, Brownlie J. Strain typing of Mycoplasma cynos isolates from dogs with respiratory disease. Vet Microbiol. 2009;135(3-4):292-296.

31. Renshaw RW, Zylich NC, Laverack MA, Glaser AL, Dubovi EJ. Pneumovirus in dogs with acute respiratory disease. Emerg Infect Dis. 2010;16(6):993-995.

32. Ford RB. Canine infectious tracheobronchitis. In: Greene CE, editor. Infectious Diseases of the Dog and Cat. 3rd ed. St Louis MO: Saunders Elsevier; 2006:54-61.

33. Welborn LV, DeVries JG, Ford R, et al. 2011 AAHA canine vaccination guidelines. J Am Anim Hosp Assoc. 2011;47(5):1-42.

34. Day MJ, Horzinek MC, Schultz RD. WSAVA guidelines for the vaccination of dogs and cats. J Small Anim Pract. 2010;51(6):1-32.

35. Sumner CM, Rozanski EA, Sharp CR, Shaw SP. The use of deep oral swabs as a surrogate for transoral tracheal wash to obtain bacterial cultures in dogs with pneumonia. J Vet Emerg Crit Care (San Antonio) 2011;21(5):515-520.

36. Greene CE, Reinero CN. Bacterial respiratory infetions. In: Greene CE, editor. Infectious Diseases of the Dog and Cat. St Louis MO: Saunders Elsevier; 2006:866-882.

37. Thrusfield MV, Aitken CGG, Muirhead RH. A field investigation of kennel cough: efficacy of different treatments. J Small Anim Pract. 1991;32(9):455-459.

38. Deshpande MS, Jirjis FF, Tubbs AL, et al. Evaluation of the efficacy of a canine influenza virus (H3N8) vaccine in dogs following experimental challenge. Vet Ther. 2009;10(3):103-112.

39. Damian M, Morales E, Salas G, Trigo FJ. Immunohistochemical detection of antigens of distemper, adenovirus and parainfluenza viruses in domestic dogs with pneumonia. J Comp Pathol. 2005;133(4): 289-293.

40. Okita M, Yanai T, Ochikubo F, et al. Histopathological features of canine distemper recently observed in Japan. J Comp Pathol. 1997;116(4): 403-408.

41. Almes KM, Janardhan KS, Anderson J, Hesse RA, Patton KM. Fatal canine adenoviral pneumonia in two litters of Bulldogs. J Vet Diagn Invest. 2010;22(5):780-784.

42. Renshaw R, Laverack M, Zylich N, Glaser A, Dubovi E. Genomic analysis of a pneumovirus isolated from dogs with acute respiratory disease. Vet Microbiol. 2011;150(1-2):88-95.

43. Ellis JA, McLean N, Hupaelo R, Haines DM. Detection of coronavirus in cases of tracheobronchitis in dogs: a retrospective study from 1971 to 2003. Can Vet J. 2005;46(5):447-448

44. Epstein SE, Mellema MS, Hopper K. Airway microbial culture and susceptibility patterns in dogs and cats with respiratory disease of varying severity. J Vet Emerg Crit Care (San Antonio). 2010;20(6):587-594.

45. Paniker CK, Nair CM. Experimental infection of animals with influenzavirus types A and B. Bull World Health Organ. 1972;47(4): 461-463.

46. Gibbs EP, Anderson TC. Equine and canine influenza: a review of current events. Anim Health Res Rev. 2010;11(1):43-51.

47. Payungporn S, Crawford PC, Kouo TS, et al. Influenza A virus (H3N8) in dogs with respiratory disease, Florida. Emerg Infect Dis 2008;14(6):902-908

48. Crawford PC, Dubovi EJ, Castleman WL, et al. Transmission of equine influenza virus to dogs. Science. 2005;310(5747):482-485.

49. Daly JM, Blunden AS, Macrae S, et al. Transmission of equine influenza virus to English foxhounds. Emerg Infect Dis. 2008;14(3):461-464.

50. Kirkland PD, Finlaison DS, Crispe E, Hurt AC. Influenza virus transmission from horses to dogs, Australia. Emerg Infect Dis. 2010;16(4):699-702.
51. Kruth SA, Carman S, Weese JS. Seroprevalence of antibodies to canine influenza virus in dogs in Ontario. Can Vet J. 2008;49(8):800-802.

52. Fouchier RA, Munster V, Wallensten A, et al. Characterization of a novel influenza A virus hemagglutinin subtype (H16) obtained from black-headed gulls. J Virol. 2005;79(5):2814-2822.

53. Yoon KJ, Cooper VL, Schwartz KJ, et al. Influenza virus infection in racing greyhounds. Emerg Infect Dis. 2005;11(12):1974-1976.

54. Lee C, Song D, Kang B, et al. A serological survey of avian origin canine H3N2 influenza virus in dogs in Korea. Vet Microbiol. 2009; 137(3-4):359-362.

55. Song D, Kang B, Lee C, et al. Transmission of avian influenza virus (H3N2) to dogs. Emerg Infect Dis. 2008;14(5):741-746.

56. Li S, Shi Z, Jiao P, et al. Avian-origin H3N2 canine influenza A viruses in Southern China. Infect Genet Evol. 2010;10(8):1286-1288.

57. Song D, Lee C, Kang B, et al. Experimental infection of dogs with avian-origin canine influenza A virus (H3N2). Emerg Infect Dis. 2009; 15(1):56-58.

58. Jung K, Lee CS, Kang BK, Park BK, Oh JS, Song DS. Pathology in dogs with experimental canine H3N2 influenza virus infection. Res Vet Sci. 2010;88(3):523-527.

59. Harder TC, Vahlenkamp TW. Influenza virus infections in dogs and cats. Vet Immunol Immunopathol. 2010;134(1-2):54-60.

60. Amonsin A, Songserm T, Chutinimitkul S, et al. Genetic analysis of influenza A virus (H5N1) derived from domestic cat and dog in Thailand. Arch Virol. 2007;152(10):1925-1933.

61. Maas R, Tacken M, Ruuls L, Koch G, van Rooij E, StockhofeZurwieden N. Avian influenza (H5N1) susceptibility and receptors in dogs. Emerg Infect Dis. 2007;13(8):1219-1221.

62. Giese M, Harder TC, Teifke JP, et al. Experimental infection and natural contact exposure of dogs with avian influenza virus (H5N1). Emerg Infect Dis. 2008;14(2):308-310.

63. Song D, Moon H, Jung K, et al. Association between nasal shedding and fever that influenza A (H3N2) induces in dogs. Virol J. 2011;8(1):1.

64. Song DS, An DJ, Moon HJ, et al. Interspecies transmission of the canine influenza H3N2 virus to domestic cats in South Korea, 2010. J Gen Virol. 2011;92(Pt 10):2350-2355.

65. Dubovi EJ. Canine influenza. Vet Clin North Am Small Anim Pract. 2010;40(6):1063-1071.

66. Shinya K, Makino A, Kawaoka Y. Emerging and reemerging influenza virus infections. Vet Pathol. 2010;47(1):53-57.

67. Castleman WL, Powe JR, Crawford PC, et al. Canine H3N8 influenza virus infection in dogs and mice. Vet Pathol. 2010;47(3):507-517.

68. Taubenberger JK, Morens DM. The pathology of influenza virus infections. Annu Rev Pathol. 2008;3:499-522.

69. Powe JR, Castleman WL. Canine influenza virus replicates in alveolar macrophages and induces TNF-alpha. Vet Pathol. 2009;46(6): 1187-1196.

70. Rosas C, Van de Walle GR, Metzger SM, et al. Evaluation of a vectored equine herpesvirus type 1 (EHV-1) vaccine expressing $\mathrm{H} 3$ haemagglutinin in the protection of dogs against canine influenza. Vaccine. 2008;26(19):2335-2343.

71. Deshpande M, Abdelmagid O, Tubbs A, Jayappa H, Wasmoen T. Experimental reproduction of canine influenza virus $\mathrm{H} 3 \mathrm{~N} 8$ infection in young puppies. Vet Ther. 2009;10(1-2):29-39.

72. Larson LJ, Henningson J, Sharp P, et al. Efficacy of the canine influenza virus $\mathrm{H} 3 \mathrm{~N} 8$ vaccine to decrease severity of clinical disease after cochallenge with canine influenza virus and Streptococcus equi subsp. zooepidemicus. Clin Vaccine Immunol. 2011;18(4):559-564.

73. Erles K, Toomey C, Brooks HW, Brownlie J. Detection of a group 2 coronavirus in dogs with canine infectious respiratory disease. Virology. 2003;310(2):216-223

74. Zicola A, Jolly S, Mathijs E, et al. Fatal outbreaks in dogs associated with pantropic canine coronavirus in France and Belgium. J Small Anim Pract. 2012;53(5):297-300.

75. Erles K, Brownlie J. Canine respiratory coronavirus: an emerging pathogen in the canine infectious respiratory disease complex. Vet Clin North Am Small Anim Pract. 2008;38(4):815-825. 
76. Buonavoglia C, Martella V. Canine respiratory viruses. Vet Res. 2007;38(2):355-373.

77. Decaro N, Elia G, Martella V, et al. Immunity after natural exposure to enteric canine coronavirus does not provide complete protection against infection with the new pantropic CB/05 strain. Vaccine. 2010;28(3): 724-729.

78. Byun JW, Yoon SS, Woo GH, Jung BY, Joo YS. An outbreak of fatal hemorrhagic pneumonia caused by Streptococcus equi subsp. zooepidemicus in shelter dogs. J Vet Sci. 2009;10(3):269-271.

79. Priestnall SL, Erles K, Brooks HW, et al. Characterization of pneumonia due to Streptococcus equi subsp. zooepidemicus in dogs. Clin Vaccine Immunol. 2010;17(11):1790-1796.

80. Pesavento PA, Hurley KF, Bannasch MJ, Artiushin S, Timoney JF. A clonal outbreak of acute fatal hemorrhagic pneumonia in intensively housed (shelter) dogs caused by Streptococcus equi subsp. zooepidemicus. Vet Pathol. 2008;45(1):51-53.

81. AbbottY, Acke E, Khan S, et al. Zoonotic transmission of Streptococcus equi subsp. zooepidemicus from a dog to a handler. J Med Microbiol. 2010;59(Pt 1):120-123.

82. Norris CR. Fungal pneumonia. In: King LG, editor. Textbook of Respiratory Disease in Dogs and Cats. St Louis MO: Saunders Elselvier; 2004:446-455.

83. Legendre AM. Blastomycosis. In: Greene CE, editor. Infectious Diseases of the Dog and Cat. 3rd ed. St Louis MO: Saunders Elsevier; 2006:569-576.

84. Hirsh DC, Biberstein EL. Agents of systemic mycoses. In: Hirsh DC, MacLachlan NJ, Walker RL, editors. Veterinary Microbiology. 2nd ed. Ames, IA: Blackwell Publishing; 2004:285-298.

85. McCullough MJ, DiSalvo AF, Clemons KV, Park P, Stevens DA. Molecular epidemiology of Blastomyces dermatitidis. Clin Infect Dis. 2000;30(2):328-335.

86. Arceneaux KA, Taboada J, Hosgood G. Blastomycosis in dogs: 115 cases (1980-1995). J Am Vet Med Assoc. 1998;213(5):658-664.

87. Rudmann DG, Coolman BR, Perez CM, Glickman LT. Evaluation of risk factors for blastomycosis in dogs: 857 cases (1980-1990). J Am Vet Med Assoc. 1992;201(11):1754-1759.

88. Greene CE. Histoplasmosis. In: Greene CE, editor. Infectious Diseases of the Dog and Cat. 3rd ed. St Louis MO: Saunders Elsevier; 2006: $577-584$.

89. Knox KS, Hage CA. Histoplasmosis. Proc Am Thorac Soc. 2010;7(3): 169-172.

90. Holbrook ED, Rappleye CA. Histoplasma capsulatum pathogenesis: making a lifestyle switch. Curr Opin Microbiol. 2008;11(4): 318-324.

91. Greene RT. Coccidioidomycosis and paracoccidioidomycosis. In: Greene CE, editor. Infectious Diseases of the Dog and Cat. 3rd ed. St Louis MO: Saunders Elsevier; 2006:598-608.

92. Shubitz LE, Butkiewicz CD, Dial SM, Lindan CP. Incidence of coccidioides infection among dogs residing in a region in which the organism is endemic. J Am Vet Med Assoc. 2005;226(11): $1846-1850$

93. Johnson LR, Herrgesell EJ, Davidson AP, Pappagianis D. Clinical, clinicopathologic, and radiographic findings in dogs with coccidioidomycosis: 24 cases (1995-2000). J Am Vet Med Assoc. 2003; 222(4):461-466

94. Dial SM. Fungal diagnostics: current techniques and future trends. Vet Clin North Am Small Anim Pract. 2007;37(2):373-392.

95. Crews LJ, Feeney DA, Jessen CR, Newman AB, Sharkey LC. Utility of diagnostic tests for and medical treatment of pulmonary blastomycosis in dogs: 125 cases (1989-2006). J Am Vet Med Assoc. 2008;232(2):222-227.

96. Hawkins EC, DeNicola DB. Cytologic analysis of tracheal wash specimens and bronchoalveolar lavage fluid in the diagnosis of mycotic infections in dogs. J Am Vet Med Assoc. 1990;197(1):79-83.

97. Legendre AM, Walker M, Buyukmihci N, Stevens R. Canine blastomycosis: a review of 47 clinical cases. $J$ Am Vet Med Assoc. 1981;178(11):1163-1168.
98. Wood EF, O’Brien RT, Young KM. Ultrasound-guided fine-needle aspiration of focal parenchymal lesions of the lung in dogs and cats. J Vet Intern Med. 1998;12(5):338-342.

99. McMillan CJ, Taylor SM. Transtracheal aspiration in the diagnosis of pulmonary blastomycosis (17 cases: 2000-2005). Can Vet J. 2008; 49(1):53-55.

100. Kowalewich N, Hawkins EC, Skowronek AJ, Clemo FA. Identification of Histoplasma capsulatum organisms in the pleural and peritoneal effusions of a dog. J Am Vet Med Assoc. 1993;202(3):423-426.

101. VanSteenhouse JL, DeNovo RC Jr. Atypical Histoplasma capsulatum infection in a dog. J Am Vet Med Assoc. 1986;188(5):527-528.

102. Meadows RL, MacWilliams PS, Dzata G, Delauche AJ. Diagnosis of histoplasmosis in a dog by cytologic examination of CSF. Vet Clin Pathol. 1992;21(4):122-125.

103. Clinkenbeard KD, Cowell RL, Tyler RD. Disseminated histoplasmosis in dogs: 12 cases (1981-1986). J Am Vet Med Assoc. 1988;193(11): 1443-1447.

104. Clinkenbeard KD, Cowell RL, Tyler RD. Identification of Histoplasma organisms in circulating eosinophils of a dog. $J$ Am Vet Med Assoc. 1988;192(2):217-218.

105. Nelson OL, Sellon RK. Pulmonary parenchymal disease. In: Ettinger SJ, Feldman EC, editors. Textbook of Veterinary Internal Medicine: Diseases of the Dog and Cat, Volume 2. 6th ed. St Louis MO: Saunders Elsevier; 2005:1239-1266.

106. Legendre AM, Rohrbach BW, Toal RL, Rinaldi MG, Grace LL, Jones JB. Treatment of blastomycosis with itraconazole in 112 dogs. $J$ Vet Intern Med. 1996;10(6):365-371.

107. Mazepa AS, Trepanier LA, Foy DS. Retrospective comparison of the efficacy of fluconazole or itraconazole for the treatment of systemic blastomycosis in dogs. J Vet Intern Med. 2011;25(3):440-445.

108. Rubensohn M, Stack S. Coccidiomycosis in a dog. Can Vet J. 2003; 44(2):159-160.

109. Legendre AM, Selcer BA, Edwards DF, Stevens R. Treatment of canine blastomycosis with amphotericin B and ketoconazole. $J$ Am Vet Med Assoc. 1984;184(10):1249-1254.

110. Krawiec DR, McKiernan BC, Twardock AR, et al. Use of an amphotericin B lipid complex for treatment of blastomycosis in dogs. J Am Vet Med Assoc. 1996;209(12):2073-2075.

111. Schulman RL, McKiernan BC, Schaeffer DJ. Use of corticosteroids for treating dogs with airway obstruction secondary to hilar lymphadenopathy caused by chronic histoplasmosis: 16 cases (1979-1997). J Am Vet Med Assoc. 1999;214(9):1345-1348.

112. Sherding RG. Parasites of the lung. In: King LG, editor. Textbook of Respiratory Disease in Dogs and Cats. St Louis MO: Saunders Elselvier; 2004:548-558.

113. Conboy G. Helminth parasites of the canine and feline respiratory tract. Vet Clin North Am Small Anim Pract. 2009;39(6):1109-1126.

114. Yao C, O'Toole D, Driscoll M, et al. Filaroides osleri (Oslerus osleri): two case reports and a review of canid infections in North America. Vet Parasitol. 2011;179(1-3):123-129.

115. Reagan JK, Aronsohn MG. Acute onset of dyspnea associated with Oslerus osleri infection in a dog. JVet Emerg Crit Care (San Antonio). March 5, 2012. [Epub ahead of print.]

116. Levitan DM, Matz ME, Findlen CS, Fister RD. Treatment of Oslerus osleri infestation in a dog: case report and literature review. J Am Anim Hosp Assoc. 1996;32(5):435-438.

117. Barr SC, Lavelle RB, Harrigan KE, Arundel JH. Oslerus (Filaroides) osleri in a dog. Aust Vet J. 1986;63(10):334-337.

118. Bowman DD. Georgis' Parasitology for Veterinarians. 8th ed. St Louis MO: Saunders Elselvier; 2003.

119. Outerbridge CA, Taylor SM. Oslerus osleri tracheobronchitis: treatment with ivermectin in 4 dogs. Can Vet J. 1998;39(4):238-240.

120. Shaw DH, Conboy GA, Hogan PM, Horney BS. Eosinophilic bronchitis caused by Crenosoma vulpis infection in dogs. Can Vet $J$. 1996;37(6):361-363.

121. Bihr T, Conboy GA. Lungworm (Crenosoma vulpis) infection in dogs on Prince Edward Island. Can Vet J. 1999;40(8):555-559. 
122. Reilly GA, McGarry JW, Martin M, Belford C. Crenosoma vulpis, the fox lungworm, in a dog in Ireland. Vet Rec. 2000;146(26):764-765.

123. Peterson EN, Barr SC, Gould WJ 3rd, Beck KA, Bowman DD. Use of fenbendazole for treatment of Crenosoma vulpis infection in a dog. J Am Vet Med Assoc. 1993;202(9):1483-1484.

124. Conboy G. Natural infections of Crenosoma vulpis and Angiostrongylus vasorum in dogs in Atlantic Canada and their treatment with milbemycin oxime. Vet Rec. 2004;155(1):16-18.

125. Crawford P. What is your diagnosis? Filaroides hirthi infection. J Small Anim Pract. 2000;41(3):95,133-134.

126. Pinckney RD, Studer AD, Genta RM. Filaroides hirthi infection in two related dogs. J Am Vet Med Assoc. 1988;193(10):1287-1288.

127. Rubash JM. Filaroides hirthi infection in a dog. J Am Vet Med Assoc. 1986;189(2):213.

128. Burgess H, Ruotsalo K, Peregrine AS, Hanselman B, Abrams-Ogg A. Eucoleus aerophilus respiratory infection in a dog with Addison's disease. Can Vet J. 2008;49(4):389-392.

129. Traversa D, Di Cesare A, Lia RP, et al. New insights into morphological and biological features of Capillaria aerophila (Trichocephalida, Trichuridae). Parasitol Res. 2011;109 Suppl 1:S97-S104.

130. Traversa D, Di Cesare A, Milillo P, Iorio R, Otranto D. Infection by Eucoleus aerophilus in dogs and cats: is another extra-intestinal parasitic nematode of pets emerging in Italy? Res Vet Sci. 2009;87(2): 270-272.

131. Traversa D, Di Cesare A, Conboy G. Canine and feline cardiopulmonary parasitic nematodes in Europe: emerging and underestimated. Parasit Vectors. 2010;3:62.

132. Blair D, Xu ZB, Agatsuma T. Paragonimiasis and the genus Paragonimus. Adv Parasitol. 1999;42:113-222.

133. Pechman RD Jr. Pulmonary paragonimiasis in dogs and cats: a review. J Small Anim Pract. 1980;21(2):87-95.

134. Procop GW. North American paragonimiasis (caused by Paragonimus kellicotti) in the context of global paragonimiasis. Clin Microbiol Rev. 2009;22(3):415-446.
135. Lee CH, Im JG, Goo JM, et al. Serial CT findings of Paragonimus infested dogs and the micro-CT findings of the worm cysts. Korean J Radiol. 2007;8(5):372-381.

136. Palic J, Hostetter SJ, Riedesel E, Richardson-Bill R, Jarvinen JA. What is your diagnosis? Aspirate of a lung nodule in a dog. Paragonimiasis Vet Clin Pathol. 2011;40(1):99-100.

137. Dubey JP, Toussant MJ, Hoover EA, Miller TB, Sharma SP, Pechman RD. Experimental Paragonimus kellicotti infection in dogs. Vet Parasitol. 1979;5(4):325-337.

138. Kirkpatrick CE, Shelly EA. Paragonimiasis in a dog: treatment with praziquantel. J Am Vet Med Assoc. 1985;187(1):75-76.

139. Bowman DD, Frongillo MK, Johnson RC, Beck KA, Hornbuckle WE, Blue JT. Evaluation of praziquantel for treatment of experimentally induced paragonimiasis in dogs and cats. Am J Vet Res. 1991;52(1): 68-71.

140. Dubey JP, Miller TB, Sharma SP. Fenbendazole for treatment of Paragonimus kellicotti infection in dogs. $\mathrm{J}$ Am Vet Med Assoc. 1979;174(8):835-837.

141. Greene CE, Chandler FM, Lobetti R. Pneumocystosis. In: Greene CE, editor. Infectious Diseases of the Dog and Cat. 3rd ed. St Louis MO: Saunders Elselvier; 2006:651-658.

142. Hughes WT. Pneumocystis carinii. In: Baron S, editor. Medical Microbiology. 3rd ed. New York: Churchill Livingstone; 1991: 1059-1063

143. Hagiwara Y, Fujiwara S, Takai H, et al. Pneumocystis carinii pneumonia in a Cavalier King Charles Spaniel. J Vet Med Sci. 2001;63(3):349-351.

144. Sukura A, Saari S, Jarvinen AK, Olsson M, Karkkainen M, Ilvesniemi T. Pneumocystis carinii pneumonia in dogs - a diagnostic challenge. J Vet Diagn Invest. 1996;8(1):124-130.

145. Lobetti RG, Leisewitz AL, Spencer JA. Pneumocystis carinii in the miniature dachshund: case report and literature review. J Small Anim Pract. 1996;37(6):280-285.
Veterinary Medicine: Research and Reports

\section{Publish your work in this journal}

Veterinary Medicine: Research and Reports is an international, peer-reviewed, open access journal publishing original research, case reports, editorials, reviews and commentaries on all areas of veterinary medicine. The manuscript management system is completely online and includes a very quick and fair peer-review system.

\section{Dovepress}

Visit http://www.dovepress.com/testimonials.php to read real quotes from published authors. 